\title{
Long-Acting Glucagon-Like Peptide-1 Receptor Agonist-Induced Rheumatoid Arthritis in a Patient with Type 2 Diabetes Mellitus
}

\author{
Koji Kikkawa ${ }^{a}$ Hiroto Hoshib $^{\mathrm{b}}$ Atsushi Isodab Kazuya Okadac Junichi Okadad \\ Takuya Watanabe ${ }^{\mathrm{e}}$ Eijiro Yamada ${ }^{\mathrm{f}}$ Kihachi Ohshima ${ }^{\mathrm{a}}$ Shuichi Okada ${ }^{\mathrm{a}} \mathrm{b}$ \\ aDepartment of Diabetes and Endocrinology, Hidaka Hospital, Takasaki, Japan; ${ }^{b}$ Department of Diabetes and \\ Endocrinology, Hoshi-iin, Maebashi, Japan; 'Department of Diabetes and Endocrinology, Omagari Kosei Medical \\ Center, Daisen, Japan; 'Division of Endocrinology, Department of Medicine, Albert Einstein College of Medicine, \\ Bronx, NY, USA; 'Department of Endocrinology and Metabolism, Saku Central Hospital Advanced Care Center, \\ Saku, Japan; fDepartment of Medicine and Molecular Science, Gunma University Graduate School of Medicine, \\ Maebashi, Japan
}

\section{Keywords}

Adverse drug reactions - Rheumatoid arthritis - Glucagonlike peptide-1 receptor agonist

\begin{abstract}
Case Presentation: We report a case of a male patient with rheumatoid arthritis (RA) diagnosed during treatment with a long-acting glucagon-like peptide-1 (GLP-1) receptor agonist (once-weekly dulaglutide injection). At 3 months after dulaglutide initiation, he began experiencing left shoulder pain that continued despite treatment by an acupuncturist, indicating that the pain was not due to periarthritis scapulohumeralis. His $\mathrm{HbA} 1 \mathrm{c}$ level was $7.3 \%$ at the 3-month followup. At the 6-month follow-up visit, the $\mathrm{HbA1}$ c level was $8.2 \%$, the low-density lipoprotein cholesterol level was $132 \mathrm{mg} / \mathrm{dL}$, and he expressed right shoulder pain. After 3 months, the $\mathrm{HbA1c}$ level was $9.0 \%$, and his bilateral shoulder pain worsened, due to which he could not use his arms well. Routine laboratory testing revealed no other abnormalities at that time. However, several inflammatory and serological RA markers were detected, including an erythrocyte sedimenta-
\end{abstract}

tion rate of 73 (normal range, $<10$ ) $\mathrm{mm} / \mathrm{h}$, a C-reactive protein level of 1.89 (normal range, $0.0-0.14$ ) $\mathrm{mg} / \mathrm{dL}$, a rheumatoid factor level of 26 (normal range, $0-15$ ) IU/mL, and an anti-cyclic citrullinated protein antibody level of 195 (normal range, $<4.5) \mathrm{U} / \mathrm{mL}$. However, tests for antinuclear antibodies, anti-SS-A/Ro antibodies, and anti-RNP antibodies showed negative results. He was diagnosed with $\mathrm{RA}$, and salazosulfapyridine $(500 \mathrm{mg} /$ day) was started. At 1 month after RA treatment initiation, his shoulder pain began showing improvement and improved HbA1c levels from $9.0 \%$ to $8.0 \%$. Discussion: Thus, this case report suggests an association between RA and GLP-1. Based on a literature search in PubMed, we believe that this case report is the first to demonstrate that a patient with type 2 diabetes mellitus treated with a long-acting GLP-1 receptor agonist had RA. However, further research is needed to determine whether RA is one of the adverse effects of long-acting GLP-1 receptor agonists. Conclusion: During treatment with long-acting GLP-1 receptor agonists, it is necessary to consider the possibility of RA as a differential diagnosis when patients complain of persistent joint pain.

(c) 2021 The Author(s)

Published by S. Karger AG, Basel karger@karger.com www.karger.com/dde

Karger $\stackrel{\text { ' }}{5}$

BOPEN ACCESS
(C) 2021 The Author(s)

Published by S. Karger AG, Basel

This is an Open Access article licensed under the Creative Common Attribution-NonCommercial-4.0 International License (CC BY-NC) (http://www.karger.com/Services/OpenAccessLicense), applicable to the online version of the article only. Usage and distribution for commercial purposes requires written permission.
Correspondence to:

Shuichi Okada,okadash1823@gmail.com 


\section{Introduction}

Rheumatoid arthritis (RA) is a chronic inflammatory autoimmune disease of unknown etiology, characterized by degradation of the cartilage and bone and accompanied by the unimpeded proliferation of synoviocytes with altered phenotype. This case report suggests that an association exists between RA and glucagon-like peptide-1 (GLP-1). GLP-1 is the most powerful incretin in humans. It also contributes to the ileal brake, accelerates glucosedependent insulin release, inhibits glucagon secretion, and increases pancreatic $\beta$-cell growth. In addition to lowering plasma glucose levels, GLP-1 exhibits anti-inflammatory properties in vivo and in vitro [1]. GLP-1 also reduced macrophage infiltration and directly inhibited inflammatory pathways in adipocytes and adipose tissue macrophages in an obese mouse model of diabetes [2]. The selective GLP-1 agonist exenatide is a licensed drug used in type 2 diabetes mellitus (T2DM) treatment. Exenatide may regulate TNF- $\alpha$-induced mitochondrial dysfunction [3]. Dulaglutide exerted powerful protective effect by rescuing mitochondrial membrane potential, inhibiting NOX-4 production, and abrogating TNF- $\alpha-$ induced downregulation of antioxidants [4]. Dulaglutide ameliorates the expression of proinflammatory cytokines and chemokines; hence, it can be used to prevent or treat RA [5]. In contrast to these reports, occasional cases of bilateral, symmetrical, seronegative polyarthritis have been reported in patients treated with DPP4, increasing the levels of incretins such as gastric inhibitory peptide GLP-1 [6]. Furthermore, the incidence of arthralgia tended to increase in some trials with the same agents, although the differences were not statistically significant [7, 8]. Concomitant with this line of evidence, polyarthritis was observed during treatment with a high-dose GLP-1 receptor agonist (1.8 $\mathrm{mg} /$ day of liraglutide) [3]. We report a case of RA diagnosed during treatment with a long-acting GLP-1 receptor agonist (once-weekly dulaglutide injection).

\section{Case Report/Case Presentation}

An 82-year-old Japanese man was referred to our clinic from a nearby general hospital to treat T2DM and hypercholesterolemia. T2DM diagnosis was made 28 years previously. Tests for glutamic acid decarboxylase antibody showed negative results throughout his clinical course. He was taking an a-glucosidase inhibitor, mitiglinide, ipragliflozin, and a long-acting dulaglutide $(0.9 \mathrm{mg} /$ day $)$ in a weekly subcutaneous injection. He was also prescribed pravastatin. His blood pressure was normal, and his BMI was $22.3 \mathrm{~kg} / \mathrm{m}^{2}$. His low-density lipoprotein cholesterol level was $142 \mathrm{mg} / \mathrm{dL}$, with

Long-Acting GLP-1 Receptor Agonist and Rheumatoid Arthritis normal high-density lipoprotein cholesterol and triglyceride levels, and his creatinine level was $1.17 \mathrm{mg} / \mathrm{dL}$. His fundus examination, vibratory sensation threshold, and ankle-brachial index were normal, indicating the absence of retinopathy, neuropathy, and peripheral artery disease. Routine laboratory testing (including microalbuminuria) revealed no other abnormalities. Three months after the dulaglutide initiation, he began experiencing left shoulder pain that continued despite treatment by an acupuncturist, which thus indicated that the pain was not due to periarthritis scapulohumeralis. His HbA1c level was 7.3\% at the 3-month follow-up. At the 6-month follow-up, the HbA1c level was $8.2 \%$, the LDL cholesterol level was $132 \mathrm{mg} / \mathrm{dL}$, and he expressed right shoulder pain as well. After 3 months, the HbA1c level was $9.0 \%$, and his bilateral shoulder pain worsened, due to which he could not use his arms well. Routine laboratory testing revealed no other abnormalities. However, several inflammatory and serological RA markers were detected, including an erythrocyte sedimentation rate of 73 (normal range, $<10) \mathrm{mm} / \mathrm{h}$, a C-reactive protein level of 1.89 (normal range, $0.0-0.14) \mathrm{mg} / \mathrm{dL}$, a rheumatoid factor level of 26 (normal range, $0-15) \mathrm{IU} / \mathrm{mL}$, and an anti-cyclic citrullinated protein antibody level of 195 (normal range, <4.5) U/mL. However, tests for antinuclear antibodies, anti-SS-A/Ro antibodies, and anti-RNP antibodies showed negative findings. X-ray examinations (plain radiography) of hands, wrists, and shoulders indicated normal findings. Ultrasound, magnetic resonance imaging, and computed tomography were not performed. He was diagnosed with RA and started on salazosulfapyridine ( $500 \mathrm{mg} /$ day). After 1 month of RA treatment initiation, his shoulder pain started showing improvement and improved HbAlc levels from $9.0 \%$ to $8.0 \%$. After another month, GLP-1 receptor agonist was terminated. His shoulder pain showed further improvement concomitant with a reduction in the measurement values of C-reactive protein, erythrocyte sedimentation rate, and rheumatoid factor $(0.01 \mathrm{mg} / \mathrm{dL}, 9 \mathrm{~mm} / \mathrm{h}$, and $12 \mathrm{IU} / \mathrm{mL}$, respectively).

\section{Discussion/Conclusion}

The patient complained of shoulder pain $>6$ months before with no other joint pain. According to the American College of Rheumatology/European League Against Rheumatism classification criteria for RA, our patient scored 5. Was our patient suffering from RA? There are several reports of shoulder joint symptoms caused by RA $[9,10]$. Especially, patients with elderly onset RA more often have large joint involvement and shoulder symptoms than patients with younger-onset RA [11-13]. In those reports, shoulder arthritis was one symptom of polyarthritis. Although a careful differential diagnosis between shoulder monoarthritis at RA onset and shoulder periarthritis and the rotator cuff tear is essential, studies have reported that $1.8 \%$ of patients had shoulder monoarthritis at RA onset $[12,14]$. Several possibilities can be considered despite the lack of reports on the mechanism and relationship between GLP-1 and RA. Previously de- 
scribed cases of DPP4i-associated polyarthritis were attributable to the direct effect of the drug on inflammatory cells expressing the enzyme [4]. In our patient, the effect cannot be mediated by DPP4, but it may be a consequence of GLP-1 receptor stimulation. However, as RA occurred during treatment with GLP-1 receptor agonists, a different mechanism mediated by GLP-1 receptor stimulation can be suggested, considering that because DPP4 degrades endogenous GLP-1, the in vivo half-life of GLP-1 is relatively short. However, dulaglutide is not degraded by DPP 4 because of the substitution of amino acids that are recognition sites as a substrate for DPP4. Therefore, although endogenous GLP-1 levels in humans are 13-41 $\mathrm{pg} / \mathrm{mL}$, the dulaglutide concentration reaches $\sim 50 \mathrm{ng} / \mathrm{mL}$ in vivo [15]. Therefore, as high GLP-1 concentrations are maintained in vivo, adverse effects might occur due to an excess amount of GLP-1 receptor agonist through interaction between GLP-1-like molecules and other binding sites different from the GLP-1 receptor. Specifically, the interaction between GLP-1-like molecules and other binding sites different from the "typical" GLP-1 receptor may induce arthritis; an experimental study supports the latter explanation, demonstrating the possibility of GLP1 interacting with the GPI/IPG-coupled receptor [16]. Concomitant with the increased inflammatory changes after treatment by the acupuncturist alone, the HbAlc levels in our patient worsened. Based on a literature search in PubMed, we believe that this case report is the first to show that a patient with T2DM treated with a long-acting GLP-1 receptor agonist had RA. However, further investigations are required to determine whether RA is one of the adverse effects of long-acting GLP-1 receptor agonists. Finally, it was difficult to eliminate the possibility that GLP-1 receptor agonist uncovered a preclinical phase of RA in our case [17]. Similarly, as we do not have previous clinical data, we could not determine whether our patient had already suffered from RA before administering GLP- 1 receptor agonist. These 2 issues remain unclear. As our clinical case appeared to be the first report to suggest that GLP-1 receptor agonist causes RA based on a literature search in PubMed, our patient might be a very rare case. Further accumulation of similar cases and analysis of those cases are required to confirm the association between GLP-1 receptor agonist and RA. Nevertheless, clinicians must pay attention to symptoms of joint pain as a rare accepted side effect when they start prescribing GLP-1 receptor agonist at this stage. During treatment with long-acting GLP-1 receptor agonists, it is essential to consider the possibility of RA as a differential diagnosis when patients complain of persistent joint pain.

\section{Acknowledgment}

The manuscript was edited by the MARUZEN Editing service.

\section{Statement of Ethics}

This case report was reviewed and approved by the review boards of Hoshi-iin (3-1) and complied with the Declaration of Helsinki. The patient provided written informed consent for the publication of this manuscript and any accompanying images. A copy of written consent is available for review by the Editor-inChief of this journal.

\section{Conflict of Interest Statement}

The authors have no conflicts of interest to declare.

\section{Funding Sources}

No funding was received.

\section{Author Contributions}

H.H., A.I., and S.O. took care of the patient. K.K., H.H., A.I., K.O. (Okada), J.O., T.W., E.Y., K.O. (Ohshima), and S.O. attended the conference and pointed out important points. K.K., K.O. (Ohshima), J.O., and S.O. prepared the manuscript.

\section{Data Availability Statement}

The datasets generated or analyzed during the current study are available from the corresponding author on reasonable request.

\section{References}

1 Shiraki A, Oyama J, Komoda H, Asaka M, Komatsu A, Sakuma M, et al. The glucagonlike peptide 1 analog liraglutide reduces TNFa-induced oxidative stress and inflammation in endothelial cells. Atherosclerosis. 2012 Apr;221(2):375-82.

2 Lee YS, Park MS, Choung JS, Kim SS, Oh HH, Choi CS, et al. Glucagon-like peptide-1 inhibits adipose tissue macrophage infiltration and inflammation in an obese mouse model of diabetes. Diabetologia. 2012;55(9):2456-68

3 Ambrosio ML, Monami M, Sati L, Marchionni N, Di Bari M, Mannucci E, et al. GLP-1 receptor agonist-induced polyarthritis: a case report. Acta Diabetol. 2014;51(4):673-4.

4 Luo X, Hu Y, He S, Ye Q, Lv Z, Liu J, et al Dulaglutide inhibits high glucose-induced endothelial dysfunction and NLRP3 inflammasome activation. Arch Biochem Biophys. 2019 Aug;671:203-9. 
5 Zheng W, Pan H, Wei L, Gao F, Lin X. Dulaglutide mitigates inflammatory response in fibroblast-like synoviocytes. Int Immunopharmacol. 2019;74:105649.

6 Crickx E, Marroun I, Veyrie C, Le Beller C, Schoindre Y, Bouilloud F, et al. DPP4 inhibitor-induced polyarthritis: a report of three cases. Rheumatol Int. $2014 \mathrm{Feb}$;34(2):291-2.

7 Nauck MA, Meier JJ. The enteroinsular axis may mediate the diabetogenic effects of TCF7L2 polymorphisms. Diabetologia. 2007 Dec;50(12):2413-6.

8 Aschner P, Kipnes MS, Lunceford JK, Sanchez M, Mickel C, Williams-Herman DE. Effect of the dipeptidyl peptidase-4 inhibitor sitagliptin as monotherapy on glycemic control in patients with type 2 diabetes. Diabetes Care. 2006 Mar;29(12):2632-7.
9 Thomas T, Noël E, Goupille P, Duquesnoy B, Combe B, GREP. The rheumatoid shoulder: current consensus on diagnosis and treatment. Joint Bone Spine. 2006;73(2):139-43.

10 Lehtinen JT, Kaarela K, Belt EA, Kautiainen HJ, Kauppi MJ, Lehto MU. Incidence of acromioclavicular joint involvement in rheumatoid arthritis: a 15 year endpoint study. J Rheumatol. 1999 Jun;26(6):1239-41.

11 Calvo-Alen J, Corrales A, Sanchez-Andrada S, Fernández-Echevarría MA, Peña JL, Rodríguez-Valverde V. Outcome of late-onset rheumatoid arthritis. Clin Rheumatol. 2005 Sep;24(5):485-9.

12 Rexhepi S, Rexhepi M, Sahatçiu-Mekaiu-Meka V, Rexhepi B, Bahtiri E, Mahmutaj V. Late onset rheumatoid arthritis an observational study. Reumatizam. 2016;63(1):1-5.

13 El-Labban AS, Omar HA, El-Shereif RR, Ali F, El-Mansoury TM. Pattern of young and old onset rheumatoid arthritis (YORA and EORA) among a group of Egyptian patients with rheumatoid arthritis. Clin Med Insights Arthritis Musculoskelet Disord. 2010;3:25-31.
14 Ishida K, Nagira K, Hagino H, Enokida M, Hayashi I, Hayashibara M, et al. Rheumatoid arthritis onset from shoulder monoarthritis. Open Access Rheumatol. 2021 May;13:103-9.

15 Smith LL, Mosley JF, Parke C, Brown J, Barris LS, Phan LD. Dulaglutide (Trulicity): the third once-weekly GLP-1 agonist. P T. 2016 Jun;41(6):357-60.

16 Nuche-Berenguer B, Portal-Núñez S, Moreno P, González N, Acitores A, López-Herradón $A$, et al. Presence of a functional receptor for GLP-1 in osteoblastic cells, independent of the cAMP-linked GLP-1 receptor. J Cell Physiol. 2010 Nov;225(2):585-92.

17 Petrovsk N, Prajzlerov K, Vencovský J, Šenolt L, Filkov M. The pre-clinical phase of rheumatoid arthritis: from risk factors to prevention of arthritis. Autoimmun Rev. 2021 May; 20(5):102797. 